Ingrid Piller, Jie Zhang* and Jia Li

\title{
Linguistic diversity in a time of crisis: Language challenges of the COVID-19 pandemic
}

https://doi.org/10.1515/multi-2020-0136

\begin{abstract}
Multilingual crisis communication has emerged as a global challenge during the COVID-19 pandemic. Global public health communication is characterized by the large-scale exclusion of linguistic minorities from timely highquality information. The severe limitations of multilingual crisis communication that the COVID-19 crisis has laid bare result from the dominance of English-centric global mass communication; the longstanding devaluation of minoritized languages; and the failure to consider the importance of multilingual repertoires for building trust and resilient communities. These challenges, along with possible solutions, are explored in greater detail by the articles brought together in this special issue, which present case studies from China and the global Chinese diaspora. As such, the special issue constitutes not only an exploration of the sociolinguistics of the COVID-19 crisis but also a concerted effort to open a space for intercultural dialogue within sociolinguistics. We close by contending that, in order to learn lessons from COVID-19 and to be better prepared for future crises, sociolinguistics needs to include local knowledges and grassroots practices not only as objects of investigation but in its epistemologies; needs to diversify its knowledge base and the academic voices producing that knowledge base; and needs to re-enter dialogue with policy makers and activists.
\end{abstract}

Keywords: multilingual crisis communication, Chinese public health communication, language challenges of COVID-19, intercultural dialogue in sociolinguistics, emergency linguistics, English-centric multilingualism

\footnotetext{
*Corresponding author: Jie Zhang, Zhongnan University of Economics and Law, Wuhan, China, E-mail: youlanlan@yahoo.com Ingrid Piller, Macquarie University, Sydney, Australia, E-mail: ingrid.piller@mq.edu.au Jia Li, Yunnan University, Kunming, China, E-mail: jia_li_yunnan@qq.com
} 


\section{The COVID-19 crisis as a mass communication challenge}

The COVID-19 crisis has arguably made 2020 a year of unprecedented global mass learning. When the three of us first started to talk about the novel coronavirus outbreak that put the city of Wuhan in China's Hubei province into global headline news in January 2020, the disease it causes had not even been named yet. Since then, COVID-19 has turned into a global pandemic and the name of the disease has gone from not even existing prior to February 11, 2020 ("Naming the coronavirus disease (COVID-19) and the virus that causes it," 2020) to entering the vocabulary of the vast majority of the world's eight billion people. "COVID-19" may well take the crown as the vocabulary item that has entered the linguistic repertoire of the largest number of people in the shortest amount of time.

Learning the name of the new disease, however, has constituted only a minuscule part of mass communication related to the pandemic. Almost everyone in the world has had to learn about public health concepts such as "social distancing", "droplet transmission" or "flattening the curve" to avoid getting sick. Almost everyone has had to understand the specifics of containment measures such as lockdowns, contact tracing, or mask wearing in their jurisdiction. And almost everyone has been exposed to and has had to form a view on often highly divisive public debates weighing health against the economy, linking the virus to particular social groups, or politicizing the disease. It is fair to say that never before have so many people globally engaged with the same topic of public communication.

\section{Linguistic diversity and public communication}

Global public communication is conducted only through a small number of the world's languages. Taking the languages of Wikipedia entries as a proxy for global knowledge dissemination, Piller (2016b), for instance, found that in 2015 only 291 around five percent - of the world's 5000 to 6000 languages were used on this free global knowledge repository. Most of these 291 languages only had a small number of entries while only 15 languages had more than one million entries each and thus accounted for the overwhelming majority of entries. Even within these 15 languages, English stood out accounting for 2.5 times more entries than the secondmost frequently used language on Wikipedia, which at the time of the study was Swedish. 
This means that global knowledge dissemination was woefully limited to a small number of languages as the world entered the pandemic. The global communication structure in place to deal with such a global emergency replicates this linguistic hierarchy. The international body tasked with coordinating the global response, the World Health Organization (WHO), makes information available in the six official languages of the United Nations (Arabic, Chinese, English, French, Russian, Spanish) and three additional languages (German, Hindi, Portuguese) although in practice English predominates, as it is the language of press conferences and the immediate "language of record" in a fast-changing information environment ("Coronavirus disease (COVID-19) pandemic," 2020).

WHO information is primarily directed at member states, who are then tasked with localizing relevant information for their populations through their national health authorities. This means that states have been key actors - including information providers - in this crisis. Most of the world's 195 states operate in one or two national languages only, and linguistic minorities within those states whether indigenous or migrant - face significant language barriers at the best of times. Around the world, the exclusion of linguistic minorities from fair and equitable access to social participation, including education, employment, welfare, or health is common (Avineri et al. 2018; Piller 2016a). During a disaster, the availability of timely, high-quality information becomes even more vital, not only for the general public but also health professionals and decision makers at all levels (Xiang et al. 2020). A mismatch between the language in which such information is communicated and the linguistic repertoires of those who need the information serves to exacerbate the effects of disasters on linguistic minorities in comparison to the majority population (Uekusa 2019).

States are not the only actors in our globalized world, and information circulating on traditional and social media emanates from a wide variety of social actors, ranging from media corporations via political parties to large numbers of highly diverse community groups and grassroots efforts. Some of these are specifically dedicated to making public health information available in languages insufficiently served by state actors (e.g., Haimovich \& Márquez Mora 2020; Lising 2020; Yu 2020). Others have contributed to an "infodemic", where populations who do not have access to timely, high-quality information are simultaneously being swamped with misleading information (Zarocostas 2020). A combination of language barriers, on the one hand, and low levels of trust in official communications, on the other, have made minority populations particularly vulnerable to misinformation and fake news, as has been found in Dutch (van Liempt and Kox 2020) and European Union (Burke 2020) research. 


\section{Language challenges of the COVID-19 crisis}

All these communication challenges matter because individual outcomes have greater influence on the overall course of the COVID-19 pandemic than is the case in most other disasters. As anyone can become a carrier of the virus, prevention and containment efforts minimizing the personal risk of individuals are deeply intertwined with the overall risk to the community. Against this background of the salience of linguistic diversity as part of COVID-19 crisis communication, we conceived this special issue and called for research submissions from sociolinguists engaged with the language challenges posed by COVID-19 (Piller 2020c). We were particularly interested in identifying the public health information needs of multilingual populations and how these needs were - or were not - being addressed.

In response to our call for papers we received more than 200 abstracts within three weeks by the deadline in early April (Piller 2020b). We received abstracts from around the world but mostly from the global South. This response, which by far exceeded our expectations and severely tested our capacity to select and respond effectively, demonstrates the strong desire of sociolinguistics scholars to rise to the challenges posed by the pandemic. The abstracts fell into five broad categories, which might constitute a basis for a sociolinguistics of the COVID-19 pandemic:

1. Linguistic limitations in the governmental provision of public health information and other public service communication to linguistically diverse populations in different countries and regions.

2. (In)accessibility of public health information to disadvantaged and minoritized groups, including indigenous populations, migrants and refugees, and people with disabilities.

3. Top-down and bottom-up language management efforts and strategies adopted to overcome language barriers during the crisis.

4. (Critical) discourse analyses of political speeches, media reports, and social media posts, particularly of COVID-19-related racism and discrimination.

5. Problems related to translation and multilingual terminology standards in public health information and medical research.

Given that we needed to reject more than 90 percent of submissions due to practical constraints, we eventually decided to limit this special issue to Chinese perspectives. Our reasons for doing so are twofold. To begin with, as the virus emerged in China, the country is two to three months ahead of the rest of the world in the COVID-19 crisis. Second, we hope that this special issue will open a space for 
intercultural dialogue within sociolinguistics, a discipline that has long been dominated by US- and more broadly Western-centric paradigms (Piller 2019).

The papers collected here bring three language aspects of the COVID-19 pandemic to the fore:

1. The changing role of English-centric multilingualism in global mass communication.

2. The consequences of the longstanding devaluation of minoritized languages for their effectiveness in emergency communication.

3. The importance of language repertoires for building trust and relationships.

In the following, we will discuss each of these in greater detail.

\section{What is the role of English-centric multilingualism in global crisis communication?}

English today is the undisputed global lingua franca. In the past decades, most countries outside the Anglosphere have invested heavily in ramping up their English capabilities (e.g., Phillipson 2003; Piller and Cho 2013; Takahashi 2013). China has been no exception to this trend (Zhang, in press). As a result of its phenomenal expansion of English language teaching and learning, China today has more English speakers than the United Kingdom, and - after USA, India, Nigeria, and Pakistan - China is home to the fifth-largest national population of English speakers on Earth ("List of countries by English-speaking population," 2020).

For most Chinese - and the same is true around the world - intercultural communication is today firmly associated with English (Piller 2017). This is true to such an extent that even Chinese language teaching materials aimed at foreign language learners of Chinese often use English as the medium through which Chinese language learning is mediated (Duan 2020).

The pandemic has exposed the fallacy of the belief in English as the universal solution to global communication problems in an unprecedented way, as a number of papers in this special issue show. English could neither meet the information needs of international residents and students in China and South Korea (Jang and Choi 2020; Li et al. 2020a; Zheng 2020) nor the demands of logistics communication to coordinate the international procurement of medical supplies (Zhang and $\mathrm{Wu} 2020$ ). 
China has been ramping up its multilingual capabilities beyond English for some time now, both through diversifying foreign language teaching (Zhang, in press) and through systematically building up multilingual capabilities through international education ( $\mathrm{Li}$ 2017). The pandemic has served as a catalyst to further speed up these developments while curtailing the influence of English.

Efforts to reduce reliance on English are not only due to the recognition that the monolingual paradigm of English-centric global communication excludes too many people from vital information but also to geopolitical tensions that have been heightened during the pandemic. English as a global language has always been embedded in the tension between being a global lingua franca, on the one hand, and the national language of the UK, USA, and other Anglophone countries, on the other. Using English as global lingua franca eo ipso privileges those countries who do not have to invest significant national resources into learning it as a foreign language (Gazzola and Grin 2013). Consequently, it is not surprising that this investment in English is now being subjected to critical interrogation (Li 2020a). One of the ironies of this critique of the role of English is that it is, to some extent, conducted in English. As an example, Zhu (2020) examines the use of English swearing on Chinese social media as a means to engage with COVID19-related anti-Chinese racism emanating from the USA.

\section{What is the role of minoritized languages in crisis communication?}

The Chinese world is highly multilingual and language barriers to accessing public health information are a pressing concern to linguistic minorities - both indigenous and migrant - within China, as well as in the global Chinese diaspora. Putonghua is the standard variety of Chinese Mandarin but the majority of Mandarin speakers speak non-standard varieties for daily communication. They and ethnic groups whose mother tongue is not Mandarin have to learn to speak Putonghua as a lingua franca.

Up until the outbreak of the coronavirus, Putonghua reigned supreme as the language that was to insure social inclusion across China (Grey 2017; Li 2020b; Li et al. 2019). However, the pandemic outbreak brought a fast recognition that Putonghua was insufficient to reach everyone in the nation and to ensure the widest-possible compliance with public health directives. In this, China has not been unique and many countries around the world discovered sooner or later during the pandemic that multilingual messaging was vital to stemming the spread of the virus (e.g., Ahmad 2020; Grey 2020a; Piller 2020a). 
However, the existence of multilingual messages alone does not guarantee that these messages are of sufficient quality. The quality of multilingual crisis communication can be evaluated along the following four dimensions (O'Brien et al. 2018; O’Brien and Federici 2019):

1. Availability: Is multilingual crisis information made available and is it recognized as an essential service?

2. Accessibility: Is multilingual crisis information freely accessible, delivered on multiple platforms, in multiple modes (spoken, written, signed, digital, etc.) and in all relevant languages?

3. Acceptability: Are provisions in place to ensure the accuracy and appropriateness of multilingual crisis information?

4. Adaptability: Are provisions in place to ensure that multilingual crisis communications can be adapted to shifting requirements, technological demands, diverse hazards, and the needs of mobile populations?

The realization of the importance of multilingual messaging since the beginning of the pandemic was quickly joined by a realization of the inadequacy of much multilingual crisis communication (e.g., Evans 2020; Grey 2020b; Hopkyns 2020; Li 2020). The inadequacy of multilingual messaging stems from the longstanding neglect of minority languages and the lack of investment in multilingual capabilities. Contributors to the special issue explore the tensions between the renewed valorization of minoritized languages and the limitations to their efficacy resulting precisely from their minoritized status (Bai 2020; Chen 2020a; Zhang and Wu 2020; Zheng 2020). They show that the discursive valorization of multilingualism as an index of inclusive attitudes can well go hand-in-hand with an exclusion of minoritized groups from vital health information (see also Li 2020b).

The contributions to the special issue make clear that minoritized languages need to become a key aspect of future disaster preparation. Li et al. (2020b) outline what a national emergency language competence plan might look like. They suggest building a national emergency communication plan around four dimensions:

1. Crisis stage: what are the different communication needs during preparation, rescue, and recovery phases?

2. Communication task: what are the different communication needs related to information provision, trust building, and minimizing misinformation?

3. Language type: what are the different communication needs related to the national language, indigenous languages, migrant languages, and signed languages/Braille? 
4. Capacity: what capacities related to linguistic talent, human resources, technical resources, or data bases are required to implement an effective crisis communication strategy?

\section{What is the role of language repertoires in building trust and relationships?}

The COVID-19 pandemic is not only a health crisis but has also produced a global political and spiritual crisis. Humans are social animals and contagious diseases throw the very foundations of our social lives into question. Not to be able to gather, to hug those dear to us, or to rub shoulders with passers-by in our cities is deeply disturbing to our social fabric. Not to be able to hold the hands of a dying relative compounds the grief of death. Many have found themselves separated from loved ones during the pandemic, not only due to quarantine rules but also because in our hypermobile world where easy travel had become the norm, travel restrictions have affected many and are keeping families apart. Not only has the pandemic unsettled our personal lives but it has also heightened friction between groups. Epidemics by their very nature produce stigma and sharpen social division (Briggs 2005, 2017). Given its origin in China, the COVID-19 pandemic has particularly brought anti-Chinese and anti-Asian racism to the fore (Zhang 2020) but has also become inextricably linked to the resurgence of global calls for racial justice radiating from the Black Lives Matter movement originating in the USA.

All this means that the language challenges of COVID-19 do not only relate to the dissemination of information but also to relationship building. Emergency communication is also about establishing trust and providing comfort, as Li et al. (2020b) explain in this issue.

When it comes to global communication, there is a division of labour between languages specializing in information dissemination through written genres and languages specializing in relationship building through oral genres. The pandemic has complicated the latter in two ways.

First, the devaluation of minoritized languages noted above also has washback effects on their utility in information provision, as Chen (2020a) notes when she describes the tensions between translated health information from Mandarin into Taiwan's indigenous languages, on the one hand, and the sidelined indigenous genres of health communication such as sheltering ceremonies, on the other. At the same time, the pandemic has yet again highlighted the strong connection between language choice and emotional response (Pavlenko 2006). Minoritized Mongolians find comfort in traditional Mongolian fiddle stories (Bai 2020), 
members of the Chinese diaspora find comfort on Chinese social media (Jang and Choi 2020; Zhao and Zhang 2020), and across the East Asian cultural region, people find comfort in classical Chinese poetry (Chen 2020b).

Second, physical distancing has resulted in a crisis of face-to-face communication across languages. As a result, the use of digital communication technologies has grown exponentially. COVID-19 has taken the role of digital communication both in multilingual information dissemination (Zhang and Wu 2020; Zheng 2020) and multilingual relationship building (Bai 2020; Jang and Choi, 2020; Li et al. 2020a; Zhao and Zhang 2020; Zhu 2020) to a whole new level.

\section{Implications for sociolinguistics}

The research brought together in this special issue has been conducted during a time of global crisis. First and foremost, we wish to make a contribution to understanding multilingual crisis communication. We do so cognizant of the fact that our research does not have the benefit of distance but has been conducted as we lived through the crisis we are researching. Much has changed, even in the short few months since we issued the call for papers for this special issue in March 2020. For instance, the importance of multilingual messaging was only on the radar of a small number of activists and linguists but has since come to the attention of the mainstream media and government. The studies brought together here may well be the first concerted exploration of the language challenges raised by the COVID19 crisis and that means that they are likely to be subject to revision and to being superseded. However, beyond the contribution the special issue makes to our understanding of multilingual crisis communication, it also has significant implications for the discipline of sociolinguistics.

As we said at the beginning, one of our editorial decisions was to center Chinese sociolinguistics. This could not be timelier. For most of its existence, the disciplinary center of the field has been the Anglophone world, particularly the USA (Liddicoat 2016). As a consequence, sociolinguistics has been highly Englishcentric both in its conceptual approaches and the empirical contexts in which research is based. For vast swathes of the field, English constitutes both the data language and the metalanguage. That COVID-19 has thrown the role of English as global lingua franca into question has been pointed out above. Beyond that we believe that a paradigm shift in sociolinguistics is on the horizon. The contributions brought together here point to three key implications for the field (see also Shen 2020, for implications specifically for the field of language policy and planning). 
First, sociolinguistics needs to include local and indigenous knowledges and grassroots practices in a meaningful way for the field to move beyond its entrenched English-centric monolingual mindset (Piller 2016b). To engage with linguistic diversity in a meaningful way, we need a much greater diversity of research perspectives and researcher positionalities embedded in a much wider range of linguistic communities than has hitherto been the case.

Second, sociolinguistics, like most of the social sciences, is a product of the 20th century global order that was shaped by the Cold War and the legacies of colonialism. As that world order is unravelling, including by China taking its place among the great global powers, our frames of reference and conceptualizations of linguistic diversity will shift (Hodge 2016). To understand language in this new world order, we will need to adjust our frameworks to become more adept at dealing with multidirectionality, fuzziness, and complexity.

Third, sociolinguistics needs to re-enter dialogue with policy makers and activists. As the field came to challenge the positivism of much applied linguistics work since the late 20th century, we have too often been lost in ever greater theoretical sophistication, little turf wars promoting a variety of fashionable new terms, and chasing citations and impact factors. In the process, sociolinguistics has largely lost its connections and conversation partners outside the academy. It does not have to be this way, though, as sociolinguists from the Beijing Advanced Innovation Center for Language Resources at Beijing Language and Culture University and more than a dozen research institutes showed in their response to the COVID-19 emergency. Working collaboratively with government agencies, information technology professionals, and volunteers, they initiated numerous language access options that were vital in China's fight against COVID-19 (Li 2020). This collaboration is now being formalized to sustain a linguistic crisis response into the future: on June 24, 2020, under the guidance of the Ministry of Education, the preparatory working group for national emergency language services was officially launched (国家应急语言服务团筹建工作组正式成立 [Preparatory working group on national emergency language services officially established], 2020). Plans are now underway to include the needs of linguistically diverse populations into all levels of the Chinese national emergency preparation, response, and recovery plan. This is a lesson we hope all linguists will take away from this special issue: to have an impact, we will need to be less afraid to get our theoretical hands dirty and we will need to engage with diverse social actors and in a variety of networks to be better prepared for the next round of multilingual crisis communication. 


\section{References}

Ahmad, Rizwan. 2020. Multilingual resources key to fighting COVID-19. Available at: https://www. languageonthemove.com/multilingual-resources-key-to-fighting-covid-19/.

Avineri, Netta, Laura R. Graham, Eric J. Johnson, Robin Conley Riner, \& Jonathan Rosa. 2018. Language and social justice in practice. London: Routledge.

Bai, Gegentuul Hongye. 2020. Fighting COVID-19 with Mongolian fiddle stories. Multilingua, 39(5). 577-586.

Briggs, Charles L. 2005. Communicability, racial discourse, and disease. Annual Review of Anthropology 34. 269-291.

Briggs, Charles L. 2017. Towards communicative justice in health. Medical Anthropology 36(4). 287-304.

Burke, Fintan. 2020. The dangers of misinformation and neglecting linguistic minorities during a pandemic. Available at: https://horizon-magazine.eu/article/dangers-misinformation-andneglecting-linguistic-minorities-during-pandemic.html.

Chen, Chun-Mei. 2020a. Public health messages about COVID-19 prevention in multilingual Taiwan. Multilingua, 39(5). 597-606.

Chen, Xi. 2020b. Fighting COVID-19 in East Asia: The role of classical Chinese poetry. Multilingua, 39(5). 565-576.

Coronavirus disease (COVID-19) pandemic. 2020. Available at: https://www.who.int/ emergencies/diseases/novel-coronavirus-2019.

Duan, Wei. 2020. Can Chinese language learning reinforce English supremacy? Available at: https://www.languageonthemove.com/can-chinese-language-learning-reinforce-englishsupremacy/.

Evans, Alice. 2020. Coronavirus: Safety fears over lack of translated virus advice. BBC News. Available at: https://www.bbc.com/news/uk-53537062.

Gazzola, Michele \& François Grin. 2013. Is ELF more effective and fair than translation? An evaluation of the EU's multilingual regime. International Journal of Applied Linguistics 23(1). 93-107.

Grey, Alexandra. 2017. How do language rights affect minority languages in China? An ethnographic investigation of the Zhuang minority language under conditions of rapid social change. (PhD), Macquarie University. Available at: http://www.languageonthemove.com/ wp-content/uploads/2017/05/Grey_How_do_language_rights_affect_minority_languages. pdf.

Grey, Alexandra. 2020a. How to improve Australia's public health messaging about Covid-19. Available at: https://www.languageonthemove.com/how-to-improve-australias-publichealth-messaging-about-covid-19/.

Grey, Alexandra. 2020b. Multilingual Australia is missing out on vital COVID-19 information. Conversation. Available at: https://theconversation.com/multilingual-australia-is-missingout-on-vital-covid-19-information-no-wonder-local-councils-and-businesses-are-steppingin-141362.

Haimovich, Gregory \& Herlinda Márquez Mora. 2020. Why it's important to use Indigenous languages in health communication. Available at: https://www.languageonthemove.com/ why-its-important-to-use-indigenous-languages-in-health-communication/.

Hodge, Bob. 2016. Social semiotics for a complex world: Analysing language and social meaning. Cambridge: Wiley. 
Hopkyns, Sarah. 2020. Linguistic diversity and inclusion in the era of COVID-19. Available at: https://www.languageonthemove.com/linguistic-diversity-and-inclusion-in-the-era-ofcovid-19/.

Jang, In Chull \& Lee Jin Choi. 2020. Staying connected during COVID-19: The social and communicative role of an ethnic online community of Chinese international students in South Korea. Multilingua 39(5). 541-552.

Li, Jia. 2017. Social Reproduction and Migrant Education: A Critical Sociolinguistic Ethnography of Burmese Students' Learning Experiences at a Border High School in China. (PhD), Macquarie University. Available at: http://www.languageonthemove.com/wp-content/uploads/2017/ 05/LI_ia_Social_reproduction_and_migrant_education.pdf.

Li, Jia. 2020a. Coronavirus meets linguistic diversity. Available at: https://www. languageonthemove.com/coronavirus-meets-linguistic-diversity/.

Li, Jia. 2020b. Transnational migrant students between inclusive discourses and exclusionary practices. Multilingua 39(2). 192-212.

Li, Jia, Ai, Bin, \& Zhang, Jie. 2019. Negotiating language ideologies in learning Putonghua: Myanmar ethnic minority students' perspectives on multilingual practices in a borderland school. Journal of Multilingual and Multicultural Development 1-14. https://doi.org/10. 1080/01434632.2019.1678628.

Li, Jia, Ping Xie, Bin Ai, \& Lisheng Li. 2020a. Multilingual communication experiences of international students during the COVID-19 pandemic. Multilingua 39(5). 529-539.

$\mathrm{Li}$, Yuming. 2020. Language lessons of COVID-19 and linguistic disaster preparedness. Available at: https://www.languageonthemove.com/language-lessons-of-covid-19-and-linguisticdisaster-preparedness/.

Li, Yuming, Gaoqi Rao, Jie Zhang, \& Jia Li. 2020b. Conceptualizing national emergency language competence. Multilingua 39(5). 617-623.

Liddicoat, Anthony J. 2016. Multilingualism research in Anglophone contexts as a discursive construction of multilingual practice. Journal of Multicultural Discourses 11(1). 9-24.

Lising, Loy. 2020. COVID-19 health information campaigns in the Philippines. Available at: https://www.languageonthemove.com/covid-19-health-information-campaigns-in-thephilippines/.

List of countries by English-speaking population. 2020. Wikipedia. Available at: https://en. wikipedia.org/wiki/List_of_countries_by_English-speaking_population.

Naming the coronavirus disease (COVID-19) and the virus that causes it. 2020. Available at: https://www.who.int/emergencies/diseases/novel-coronavirus-2019/technical-guidance/ naming-the-coronavirus-disease-(covid-2019)-and-the-virus-that-causes-it.

O’Brien, Sharon, Federico Federici, Patrick Cadwell, Jay Marlowe, \& Brian Gerber. 2018. Language translation during disaster: A comparative analysis of five national approaches. International Journal of Disaster Risk Reduction 31. 627-636.

O’Brien, Sharon \& Federico Marco Federici. 2019. Crisis translation: Considering language needs in multilingual disaster settings. Disaster Prevention and Management: An International Journal. https://doi.org/10.1108/DPM-11-2018-0373.

Pavlenko, Aneta. 2006. Emotions and multilingualism. Cambridge: Cambridge University Press. Phillipson, Robert. 2003. English-only Europe? Challenging language policy. London: Routledge. Piller, Ingrid. 2016a. Linguistic diversity and social justice. Oxford and New York: Oxford University Press.

Piller, Ingrid. 2016b. Monolingual ways of seeing multilingualism. Journal of Multicultural Discourses 11(1). 25-33. 
Piller, Ingrid. 2017. Intercultural communication: A critical introduction, 2nd ed. Edinburgh: Edinburgh University Press.

Piller, Ingrid. 2019. On the conditions of authority in academic publics. Journal of SocioLinguistics 23(5). 521-528.

Piller, Ingrid. 2020a. Covid-19 forces us to take linguistic diversity seriously. In Gerhard Boomgaarden (ed.), 12 perspectives on the pandemic: International social science thought leaders reflect on Covid-19, 12-17. Berlin and New York: De Gruyter.

Piller, Ingrid. 2020b. Language challenges of Covid-19 are a pressing issue. Available at: https:// www.languageonthemove.com/language-challenges-of-covid-19-are-a-pressing-issue/.

Piller, Ingrid. 2020c. Linguistic diversity and public health: Sociolinguistic perspectives on COVID19. Available at: https://www.languageonthemove.com/linguistic-diversity-and-publichealth-sociolinguistic-perspectives-on-covid-19/.

Piller, Ingrid \& Jinhyun Cho. 2013. Neoliberalism as language policy. Language in Society 42(1). 23-44.

Shen, Qi. 2020. Commentary: Directions in language planning from the COVID-19 pandemic. Multilingua 39(5). 625-629.

Takahashi, Kimie. 2013. Language learning, gender and desire: Japanese women on the move. Clevedon: Multilingual Matters.

Uekusa, Shinya. 2019. Disaster linguicism: Linguistic minorities in disasters. Language in Society 48(3). 353-375.

van Liempt, Ilse \& Mieke Kox. 2020. Coronavirus: Misinformation is leading to 'fake news' anxieties in Dutch refugee communities. The Conversation. Available at: https:// theconversation.com/coronavirus-misinformation-is-leading-to-fake-news-anxieties-indutch-refugee-communities-141830.

Xiang, Yu-Tao, Wen Li, Qinge Zhang, Yu Jin, Wen-Wang Rao, Liang-Nan Zeng, Grace K. I. Lok, Ines H. I. Chow, Teris Cheung \& Brian J. Hall. 2020. Timely research papers about COVID-19 in China. The Lancet 395(10225). 684-685.

$\mathrm{Yu}$, Lha. 2020. Fighting the coronavirus in local languages. Available at: https://www. languageonthemove.com/fighting-the-coronavirus-in-local-languages/.

Zarocostas, John. 2020. How to fight an infodemic. The Lancet 395(10225). 676.

Zhang, Jie. 2020. Racism hinders the fight against COVID-19. Available at: https://www. languageonthemove.com/racism-hinders-the-fight-against-covid-19/.

Zhang, Jie. in press. Language policy and planning for the modern olympic games: China's experiences. Berlin and New York: De Gruyter.

Zhang, Jie \& Wu, Yuqin. 2020. Providing multilingual logistics communication in COVID-19 disaster relief. Multilingua 39(5). 517-528.

Zhao, Sumin \& Zhang, Tian Leticia. 2020. Diaspora micro-influencers and COVID communication on social media: The case of Chinese-speaking YouTube vloggers. Multilingua 39(5). 553-563.

Zheng, Yongyan. 2020. Mobilizing foreign language students for multilingual crisis translation in Shanghai. Multilingua 39(5). 587-595.

Zhu, Hongqiang. 2020. Countering COVID-19-related anti-Chinese racism with translanguaged swearing on social media. Multilingua 39(5). 607-616.

国家应急语言服务团筹建工作组正式成立 [Preparatory working group on national emergency language services officially established]. 2020. Available at: http://www.moe.gov.cn/s78/ A19/moe_814/202007/t20200706_470547.html. 